\title{
Evaluation of the uptake, retention and effectiveness of exercise referral schemes for the management of mental health conditions in primary care: a systematic review
}

\author{
Samuel Tomlinson-Perez ${ }^{1^{*}+}$ (D), Katarzyna Karolina Machaczek ${ }^{2+}$, Joseph Firth ${ }^{3}$, Nicholas Pollard ${ }^{4}$, \\ Goutham Meda', Ellis Keddie ${ }^{1}$ and Elizabeth Goyder ${ }^{5}$
}

Samuel Tomlinson-Perez and Katarzyna Karolina Machaczek are joint first authors.

\begin{abstract}
Background: Exercise is a recognised element of health-care management of mental-health conditions. In primary health care, it has been delivered through exercise referral schemes (ERS). The National Institute for Health and Care Excellence has highlighted uncertainty regarding the effectiveness of ERS in improving exercise participation and health outcomes among those referred for mental-health reasons. This review aims, therefore, to evaluate ERSs for individuals who are referred specifically for mental-health reasons.
\end{abstract}

Methods: Studies were reviewed that assessed the effectiveness of ERSs in improving initiation of and/or adherence to exercise and/or their effectiveness in improving long-term participation in exercise and health outcomes among primary care patients who had been referred to the scheme for mental-health reasons. The data were extracted and their quality assessed. Data were analysed through a narrative synthesis approach.

Results: Nine studies met the eligibility criteria. Three assessed clinical effectiveness of the schemes, eight assessed ERS uptake and/or adherence to the exercise schedule, and two assessed the impact of the ERSs on long-term exercise levels. In one study, it was found that ERSs that were based in leisure centres significantly improved long-term symptoms in those who had been referred due to their mental ill health $(P<0.05)$. ERSs that involved face-to-face consultations and telephone calls had the highest rates of mean uptake (91.5\%) and adherence (71.7\%), but a difference was observed between uptake/adherence in trials (86.8\%/55.3\%) and in routine practice (57.9\%/37.2\%). ERSs that included face-to-face consultations and telephone calls increased the amount of long-term physical activity that was undertaken by people who had been referred for mental-health reasons $(P=0.003)$.

Conclusions: Uptake and effectiveness of ERSs for mental health conditions was related to programme content and setting with more effective programmes providing both face-to-face and telephone consultations. Good uptake of yoga among those referred for mental health reasons suggests that mindful exercise options should be investigated further. Existing ERSs could be improved through application of individual tailoring and the provision of more

\footnotetext{
*Correspondence: stomlinsonperez@gmail.com ${ }^{\dagger}$
}

' School of Medicine, University of Liverpool, Liverpool, UK

Full list of author information is available at the end of the article

(C) The Author(s) 2022. Open Access This article is licensed under a Creative Commons Attribution 4.0 International License, which permits use, sharing, adaptation, distribution and reproduction in any medium or format, as long as you give appropriate credit to the original author(s) and the source, provide a link to the Creative Commons licence, and indicate if changes were made. The images or other third party material in this article are included in the article's Creative Commons licence, unless indicated otherwise in a credit line to the material. If material is not included in the article's Creative Commons licence and your intended use is not permitted by statutory regulation or exceeds the permitted use, you will need to obtain permission directly from the copyright holder. To view a copy of this licence, visit http://creativecommons.org/licenses/by/4.0/. The Creative Commons Public Domain Dedication waiver (http://creativeco mmons.org/publicdomain/zero/1.0/) applies to the data made available in this article, unless otherwise stated in a credit line to the data. 
face-to-face consultations, and social support. Further research is required to identify the types of ERSs that are most clinically effective for those with mental ill health.

Keywords: Mental health, Anxiety, Depression, Physical activity, Exercise referral schemes, Uptake, Adherence, Effectiveness

\section{Background}

Up to $15 \%$ of the UK population may experience a mental-health disorder at any one time [1]. Depression and anxiety are two of the commonest conditions. Depression is a leading cause of disability globally and is the leading cause worldwide of disability and premature deaths in adults aged 18-44 [2]. It has a prevalence of $4.5 \%$ among UK adults and is characterised by constant low mood and/or the loss of enjoyment in the majority of their activities (i.e. anhedonia), and a range of related emotional, cognitive, physical and behavioural symptoms [2]. Approximately $25 \%$ of adults experience anxiety at some point in their lives [3]. Generalised anxiety disorder is characterised by disproportionate, pervasive, uncontrollable and widespread levels of worry, with potential somatic, cognitive and behavioural symptoms [3]. Anxiety and depression form one of the most common comorbidities [4]. Approximately $67 \%$ of those with depression are thought to have a comorbid anxiety. Similarly, $63 \%$ of those with a primary anxiety disorder are likely to have concurrent depression [4]. Findings from a recent UK survey suggest that the incidence of stress has increased, with $74 \%$ of adults reporting that they feel overwhelmed or unable to cope due to mental or emotional pressures [5]. Individuals may also have multiple mental health conditions at any given time.

Primary care plays a central role in the management of mental ill-health; up to $90 \%$ of depression and anxiety cases are managed in this setting [1]. Numerous management methods are available in primary care for mental health conditions, including lifestyle advice, medication and psychotherapy. Increasing physical activity levels is a common lifestyle recommendation for many health conditions, as it has been demonstrated to improve overall health outcomes, quality of life, functional capacity and mood [6]. Physical activity is defined as any skeletal body movement that requires energy expenditure. Exercise is a subset of physical activity that is planned, structured and repetitive, with the goal of maintaining or improving fitness levels [7]. More specifically for mental health, physical activity has been shown to be effective for stress [8], clinical depression and anxiety [9]. Meanwhile, individuals not participating in regular physical activity are twice as likely to display depression and anxiety symptoms [10]. Furthermore, physical inactivity contributes towards the high levels of cardiometabolic diseases observed in people with mental illness [11].

Despite the well-known health benefits of exercise [12], many people lead sedentary lives, this is particularly the case for those with mental ill health [13]. In England, for example, $34 \%$ of men and $42 \%$ of women do not achieve the recommended amount of weekly aerobic exercise (150 min of moderate activity or $75 \mathrm{~min}$ of vigorous activity) [14]. Additionally, 27\% of adults exercise for less than $30 \mathrm{~min}$ a week and are thereby classified as inactive [15].

One way to increase activity levels among sedentary individuals is through exercise referral schemes (ERS). These consist of an assessment by primary care or allied health professionals, followed by referral to a physical activity specialist and/or service. The patient is advised on the type of physical activity that suits the specific needs of the individual and he or she is given the opportunity to take part in an exercise programme [16], often based in a leisure centre [17]. ERSs can be funded by commissioners for the rehabilitation and management of certain health conditions including myocardial infarctions, stroke, chronic heart failure, chronic obstructive pulmonary disease, lower back pain and depression [16]. Individuals with stress and anxiety are also eligible for the scheme [18]. There are currently no standardised protocols for how ERS programmes are delivered or the type of exercises that are involved. This means a variety of ERSs are offered in the UK and there are currently no set guidelines for the type of ERSs that should be used in patients referred for mental health reasons. A lack of evidence regarding effectiveness for specific schemes or population subgroups is the primary cause for this [16]. It is, however, important to stress that a lack of standardisation in ERSs for mental health referrals is not necessarily negative, with increased individualisation of exercise programmes shown to improve engagement in this clinical population [19].

A preliminary literature search highlighted a gap in evidence regarding the effectiveness of ERSs on mental health, and this is supported by the latest National Institute for Health and Care Excellence (NICE) guidance on ERSs [16]. Previous reviews have assessed mental health outcomes in ERSs as part of a wider review scope [20, 21], but none have focused on mental health specifically. Additionally, many of the studies included participants 
referred for non-mental health reasons in the assessment of mental health outcomes. To reliably evaluate ERSs as a management method for patients with mental illness, it is important to analyse the body of research which focuses on participants with mental health diagnoses as their primary reason for referral. The emphasis was placed on studies focusing on depression and anxiety since they are the most prevalent mental health disorders in the UK population [2,3]. Other mental health conditions, such as stress or post-traumatic stress disorder were also included in the review.

This review also explored the suitability of ERSs as an intervention in the real world by examining uptake and adherence. Both at the individual and population level, uptake and adherence are an important aspect of ability to benefit from an intervention. Assessing whether ERSs influence long-term physical activity levels is another important measure of effectiveness in those referred for mental health reasons. No reviews were found that explored all of these areas.

The aim of this review was to evaluate the use of ERSs as a management method for individuals referred for mental health reasons in a primary care setting. To address this aim the following primary objectives were set:

1. To assess the clinical effectiveness of ERSs on mental health symptoms in participants referred for mental health reasons.

2. To assess levels of uptake and adherence to ERSs among participants referred for mental health reasons.

3. To assess the effects of ERSs on long-term physical activity levels in participants referred for mental health reasons.
The secondary aim of this review was to assess uptake of and adherence to exercise programmes in mental health referrals compared to non-mental health referrals in included studies.

\section{Methods}

\section{Search strategy and study selection}

Adhering to PRISMA guidelines [22], a literature search was conducted in five electronic databases: MEDLINE, PsycInfo, CINAHL, Scopus, and the Cochrane Library. A pre-specified review protocol was created for ERSs in mental health conditions (Additional File 1). The review was restricted to publications written in the English language, due to a lack of translation resources. Databases were searched from inception to July 2020. The search terms included 'exercise', 'physical activity', 'referral', 'mental health', 'depression', 'mood disorders', 'affective disorders', 'anxiety', and 'anxiety disorders'. Detailed search strategies for all databases are presented in Table S1 (please see Additional file 2). Reference lists of relevant studies were scanned, and citation searches using Google Scholar were also undertaken. Deduplication was performed for all records identified. Titles and abstracts of remaining records were screened to exclude irrelevant studies. All remaining articles were read in full and selected for inclusion if they met the eligibility criteria. All titles and abstracts were reviewed by two independent reviewers (STP \& GM) to determine appropriateness to the purpose of the review. Any disagreements over study inclusion were resolved by discussion. Similarly, the two reviewers reviewed full texts independently and compared these against predefined eligibility criteria to confirm the article's appropriateness for inclusion in the review.

Table 1 Inclusion criteria based on PICO framework

\section{Inclusion Criteria}

1. Study participants were diagnosed with a mental health condition, with primary care being the main source of referral.

2. Mental health was the primary reason for referral.

3. Studies evaluating ERS, as defined by Pavey et al. [21]

o Referral by a primary-care health-care professional to a service designed to increase physical activity or exercise

o Physical activity/exercise programme tailored to individual needs

o Initial assessment and monitoring throughout the programme

4. Studies with any relevant comparator were permitted.

5. Studies had to measure one or more of the following

o Changes in clinical symptoms of mental health conditions (e.g. depression and anxiety) found or managed in primary care

o ERS uptake/adherence rates of individuals referred from primary care for mental health reasons

o Impact of ERS on long-term physical activity levels in participants referred from primary care for mental health reasons. 


\section{Eligibility Criteria}

The population, intervention, comparator, outcome (PICO) framework [23] was used to clarify inclusion criteria (please see Table 1). All quantitative study designs were eligible. Studies were excluded if mental health was not specified as a primary referral reason, they included individuals participating in regular exercise, or evaluated exercise interventions that did not meet ERS criteria. No limits were placed on duration or severity of conditions, or on age and medication use. No restrictions were placed on the type of tools used to measure outcomes or outcome assessment timings.

\section{Data extraction}

The data extraction process was undertaken by two reviewers (STP \& EK) using a piloted data extraction form. Recorded information included details of the studies (e.g. author, year, setting, study type), participants (e.g. sample size, age, gender, mental health conditions), details of intervention/comparators (e.g. type, length, frequency/duration of sessions), outcomes (e.g. primary/ secondary outcomes, outcome measures, assessment timings), and results. Authors were contacted directly if there was insufficient data to evaluate the research findings in the published paper.

\section{Quality assessment}

The risk of bias in all included articles was assessed at the study level, based on study design-specific criteria and conduct. The Cochrane Collaboration's risk of bias tool [24] was used to analyse risk of bias in randomised controlled trials (RCTs). A risk of bias graph and summary were created for RCTs with Review Manager 5.3 software [25]. The other studies were treated as case series, and were assessed using a modified version of the Institute of Health Economics Quality Appraisal Checklist [26]. A quality appraisal checklist table was created. Two reviewers (STP \& GM) independently performed quality assessment. Disagreements were resolved by discussion.

\section{Data synthesis}

Due to considerable inter-study heterogeneity, performing a meta-analysis was deemed to be inappropriate. A narrative synthesis approach was used to analyse the results for each outcome. Results data were combined for both uptake and adherence outcomes (for mental health referrals, and mental health compared to non-mental health referrals). This was performed by calculating mean values across studies based on individual participant data. Mean values were calculated for different ERS types and different study settings.

\section{Results}

\section{Study selection}

A total of 1659 records were retrieved from database searches, of which 257 records were duplicates. A further 1360 were excluded following screening of titles and abstracts (Fig. 1). After full-text screening of 52 articles, 9 manuscripts [27-35] were included in this review (Additional file 3$)$.

\section{Study characteristics}

Characteristics of the nine included [27-35] studies are shown in Table 2. Data from Murphy et al. [30] and Moore et al. [31] originated from the same trial but since they presented different outcome measures, they are referred to as separate studies.

The most common study type was a retrospective analysis of ERS data [27, 28, 33-35]; or an RCT [29-32]. Studies targeted patients treated for mental ill health [29, 32 ] or mental ill health and other chronic health conditions $[27,28,30,31,35]$.

Six studies assessed leisure centre-based ERSs $[27,28$, $30,31,33,35]$. Three of these [30,31, 35] provided access to leisure facilities and exercise sessions throughout, two in-person consultations, plus one telephone call. One [27] provided the same but without telephone contact. One [28] required participants to attend biweekly exercise classes. One [33] provided educational classes and access to exercise sessions, although no information was provided on frequency or duration.

Two studies assessed ERSs involving regular 30- to 60-minute face-to-face consultations and telephone calls with exercise professionals [29, 32]. These meetings aimed to motivate and educate participants to increase physical activity levels. One study assessed an ERS involving lifelong referral to 60-minute therapeutic yoga classes with up to eight sessions a week [34]. Apart from lifelong yoga referrals [34], all ERSs lasted 8-32 weeks. The characteristics of interventions are listed in Table 3.

\section{Quality assessment}

Additional file 4 provides further details about quality assessment. Figures S1 and S2 show the risk of bias graph and summary created for the four RCTs [29-32]. Risk of selection bias was low for two $[30,31]$ and unclear for two studies [29, 32]. Random sequence generation was achieved using a random number generator $[30,31]$ or randomisation chart [32]. Allocation concealment was ensured by allocating treatment remotely [30, 31], or using an automated telephone system [29]. All included trials were at high risk of performance bias because the nature of the intervention made it impossible to blind participants. Three studies were deemed to be at low risk of detection bias [30-32]. All studies scored at high risk 


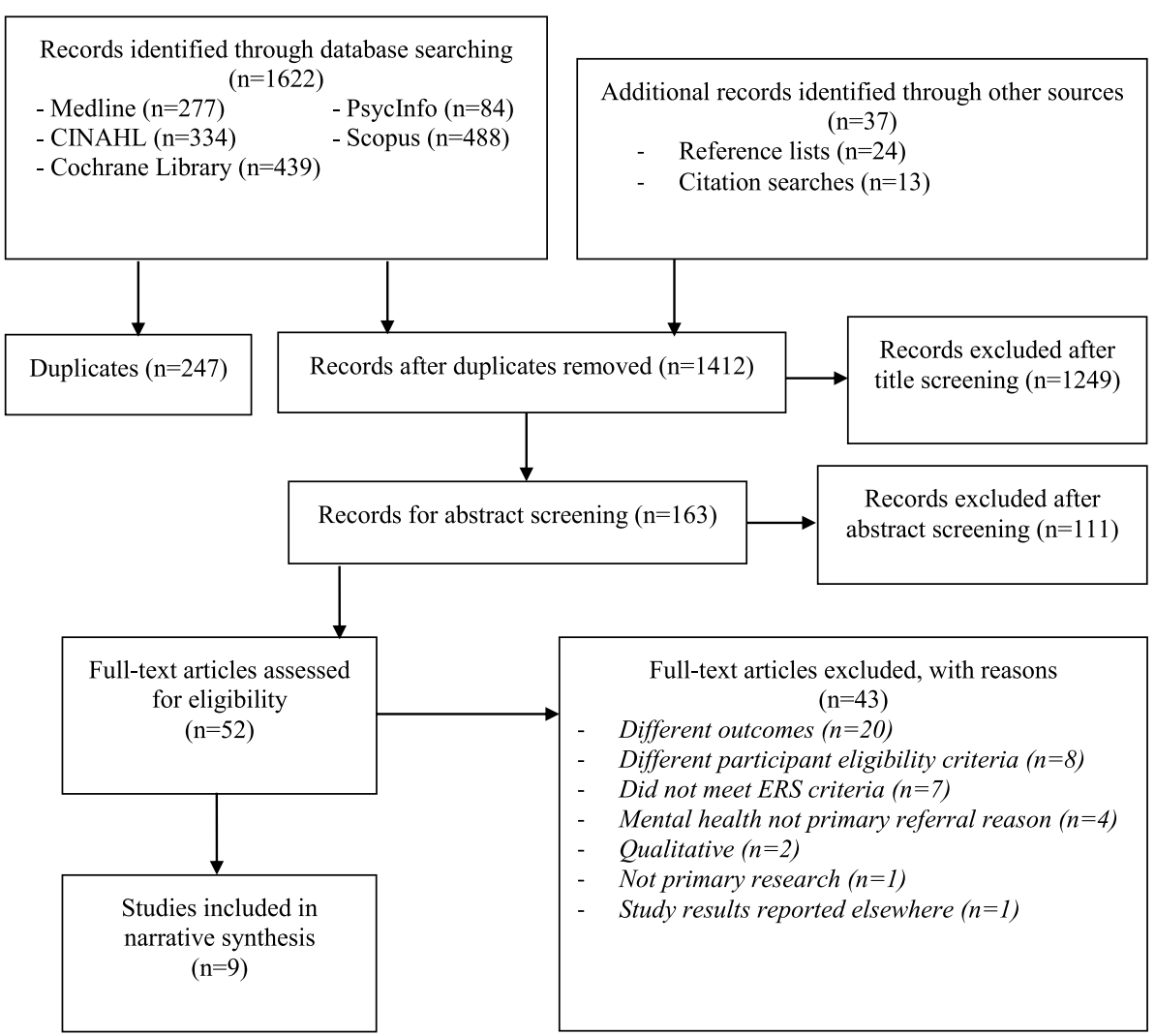

Fig. 1 Modified PRISMA flowchart of literature search results

of attrition bias. The evidence for reporting bias was not found.

Table S2 (please see Additional File 4) shows the quality appraisal checklist for the five case series studies [27, 28, 33-35]. A potential risk of bias for all studies was due to their retrospective nature. Other sources of bias included not knowing whether patients were recruited consecutively, and whether severity of mental health conditions in participants was similar.

\section{Primary outcomes}

Primary outcomes of this review were to assess clinical effectiveness of ERSs on mental health symptoms, uptake and adherence of ERS participants referred for mental health reasons, and effects of ERSs on long-term physical activity levels in mental health patients. Tables have been created for all primary outcomes (Tables 4, 5 and 6). Each table displays individual results and participant characteristics for every study pertinent to the respective outcome.

\section{Clinical effectiveness on mental health symptoms}

Three RCTs [29, 30, 32] assessed the clinical effectiveness of ERSs for mental health disorders (Table 4). Studies used a range of outcomes: Hospital Anxiety and Depression Scale (HADS); Beck Depression Inventory Version II Score (BDI-II); and Depression, Anxiety and Stress Scale (DASS-21).

When combining results from 4, 8 and 12 months, Chalder et al. [29] recorded a non-significant between group mean difference in the BDI-II score in favour of the intervention group. After adjusting for all covariates, Murphy et al. [30] found, at 12 months, that the ERS group had a significantly lower HADS anxiety $(-1.56)$ and depression (-1.39) scores compared to the control group.

\section{Uptake and adherence in mental health referrals}

Eight studies [27-29, 31-35] assessed this outcome (Table 5). Three of these were RCTs $[29,31,32]$ and five were in routine practice [27, 28, 33-35].

\section{Uptake}

Seven studies [27-29, 31, 32, 34, 35] assessed uptake of ERSs amongst patients referred for mental health reasons. Four studies [27, 28, 31, 35] used a leisure centrebased ERS, with uptake ranging from $57.5 \%$ [35] to $83.2 \%$ [31]. Mean uptake in these four studies was $58.5 \%$. Two 


\begin{tabular}{|c|c|c|c|c|c|}
\hline 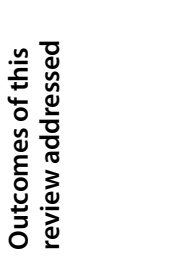 & 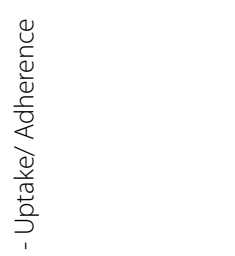 & 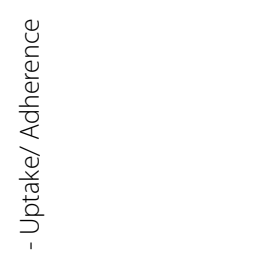 & 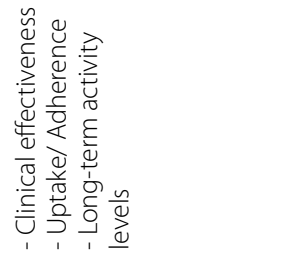 & 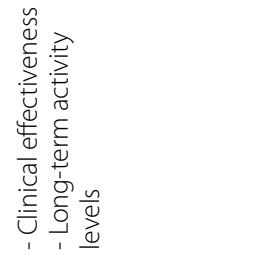 & 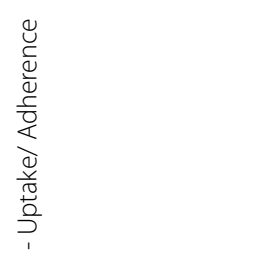 \\
\hline 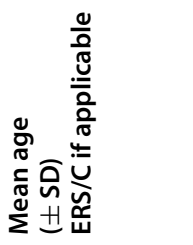 & 离 & 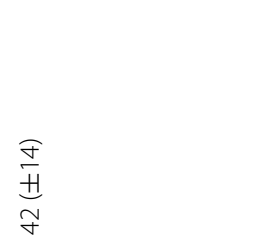 & 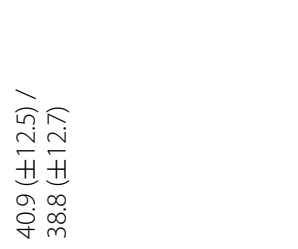 & 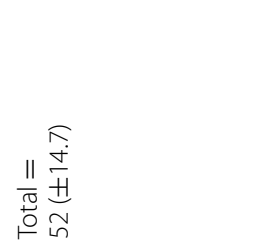 & 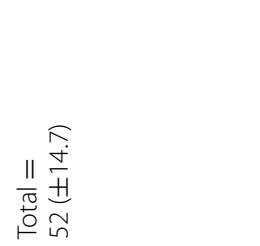 \\
\hline 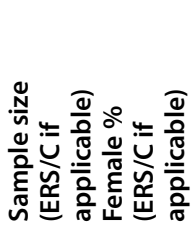 & 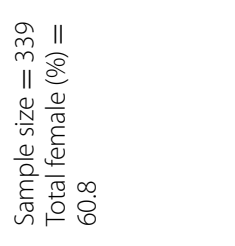 & 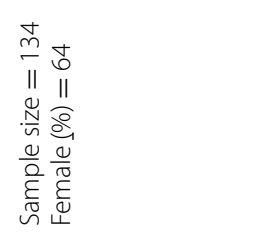 & 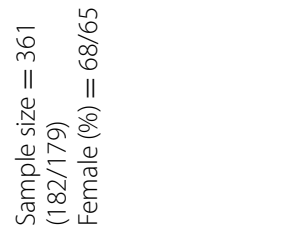 & 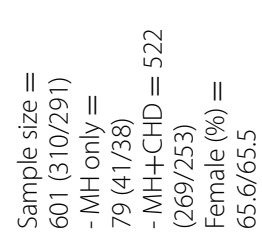 & 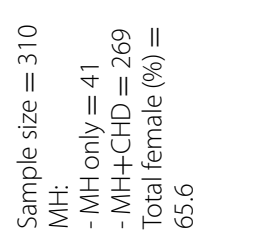 \\
\hline 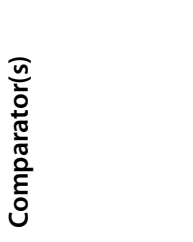 & 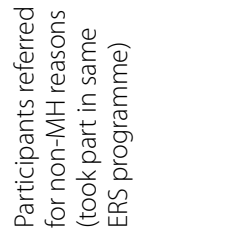 & 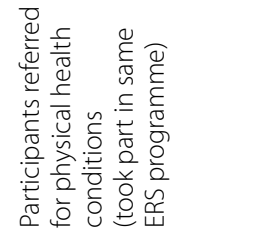 & 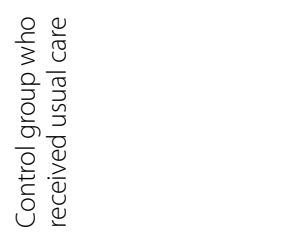 & 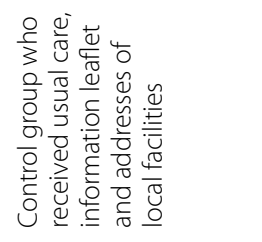 & 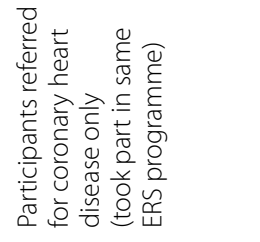 \\
\hline 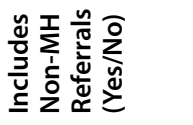 & 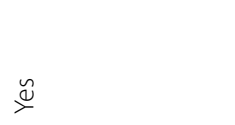 & $\stackrel{\check{\Perp}}{\rightleftharpoons}$ & 울 & $\stackrel{\Perp}{\circlearrowright}$ & $\stackrel{\check{\varpi}}{\simeq}$ \\
\hline 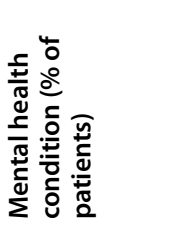 & 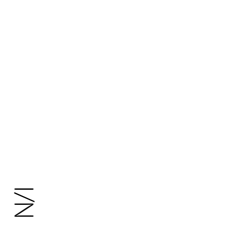 & 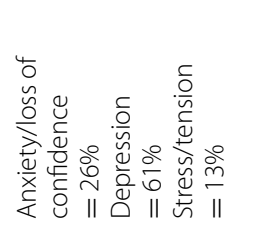 & 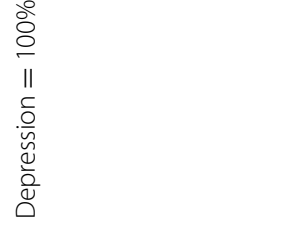 & 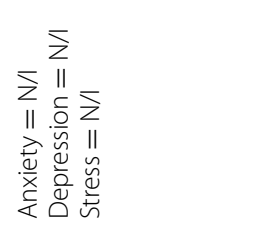 & 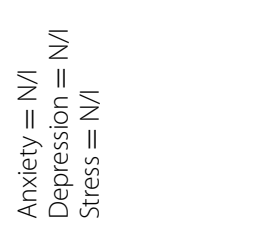 \\
\hline 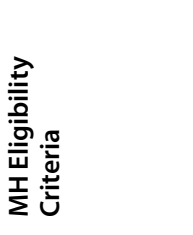 & 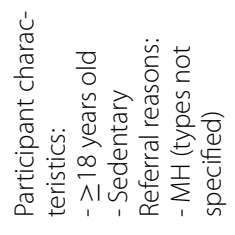 & 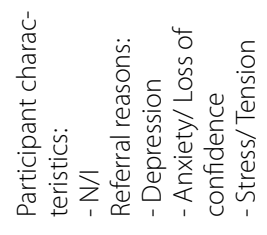 & 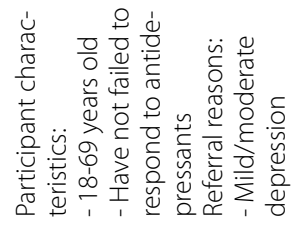 & 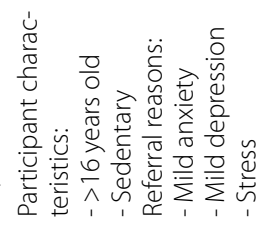 & 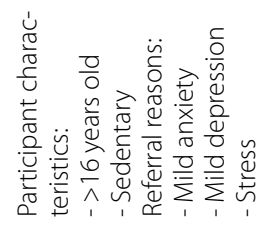 \\
\hline 产 & 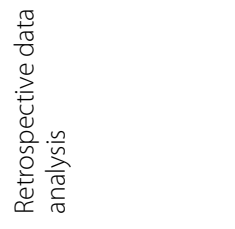 & 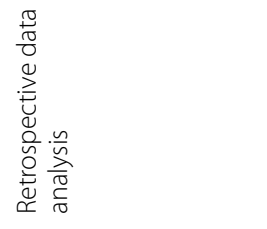 & $\underset{ð}{\longleftarrow}$ & 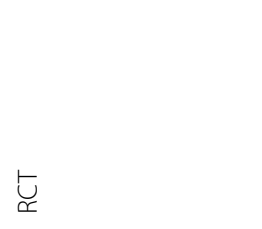 & $\underset{\propto}{\longleftarrow}$ \\
\hline 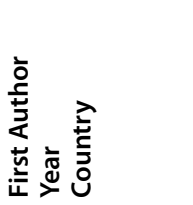 & 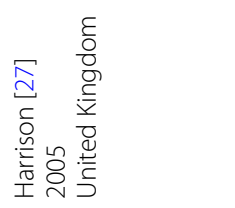 & 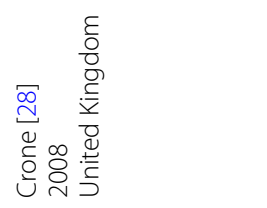 & 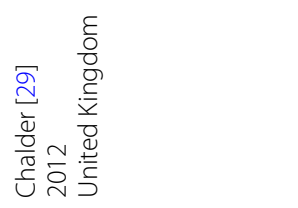 & 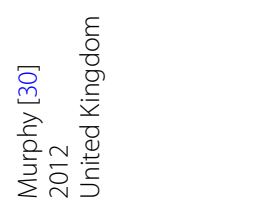 & 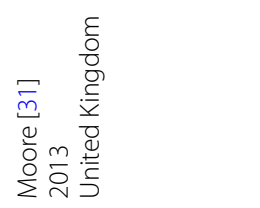 \\
\hline
\end{tabular}




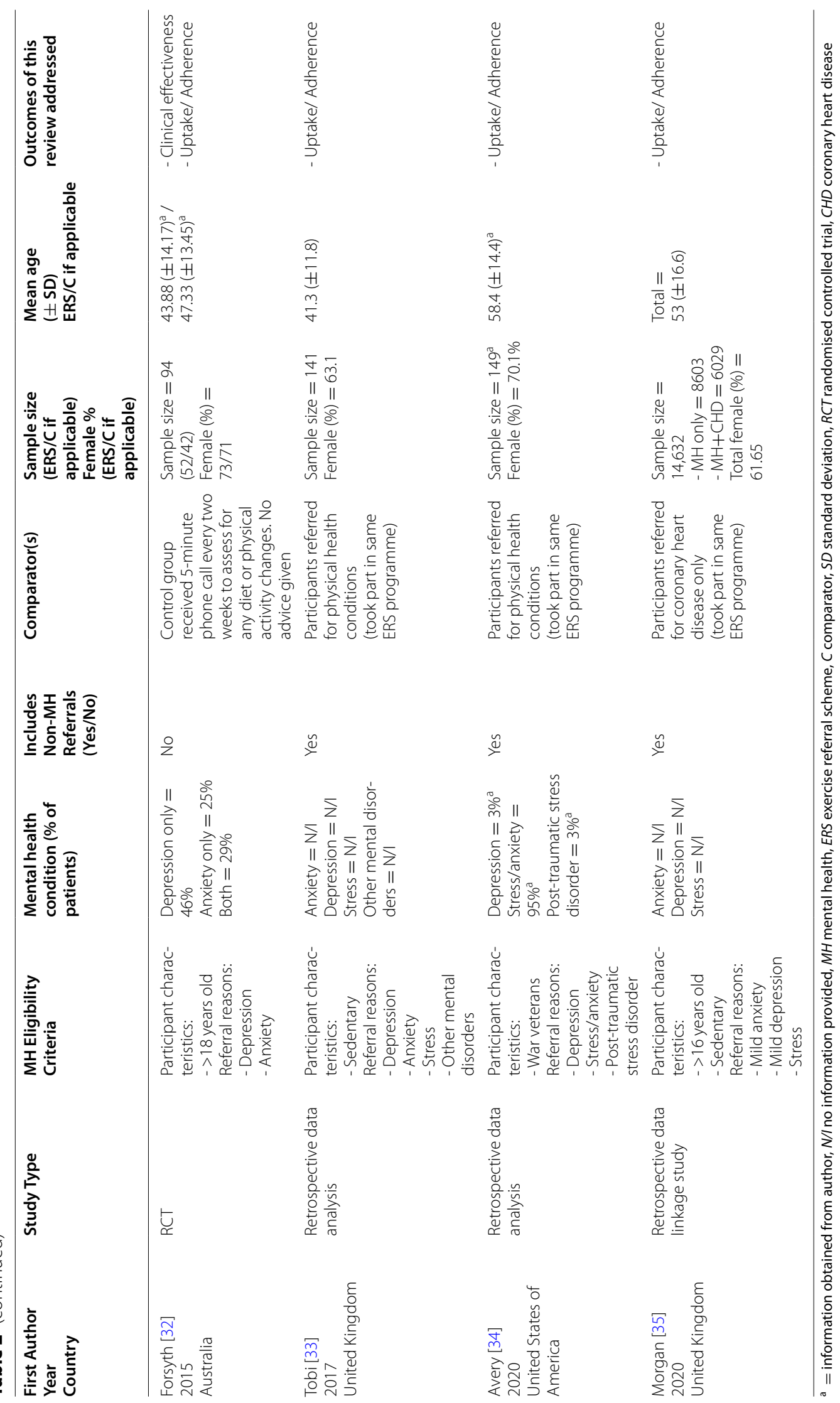


studies [29, 32] used ERSs involving regular face-to-face consultations and telephone calls. Uptake levels in these studies were $94.5 \%$ [29] and $85.2 \%$ [32]. Mean uptake across both studies was $91.5 \%$. One study [34] involved yoga classes and had an uptake of $42.3 \%$.

\section{Uptake in routine practice versus uptake in trials}

Uptake of the scheme in routine practice ranged from 42.3 to $82.6 \%$ [27, 28, 34, 35]. The mean uptake across all four studies was $57.9 \%$. The other study involved yoga classes [34] and had an uptake of $42.3 \%$. Uptake rates reported for RCTs [29, 31, 32] ranged from 83.2 to $94.5 \%$. The mean uptake across all three studies was $86.8 \%$.

\section{Adherence}

Five studies [28, 29, 31-33] assessed adherence levels to ERSs among patients referred for mental health reasons. Adherence was measured as a binary outcome in all studies and defined as whether participants completed the ERS once they had attended. Participants who attended no ERS sessions were not included in adherence calculations. Adherence levels ranged from $36.7 \%$ [28] to $75.4 \%$ [29]. Three of the studies [28, 31, 33] used a leisure centre-based ERS, with adherence levels ranging from 36.7\% [28] to $41.1 \%$ [31]. Mean adherence in these three studies was 39.3\%. The other two studies [29, 32] used ERSs involving regular face-to-face consultations and telephone calls, and had adherence levels of $75.4 \%$ [29] and $59.6 \%$ [32]. The mean adherence across both studies was $71.7 \%$. The two studies $[28,32]$ with the shortest ERSs (8-12 weeks) had a mean adherence of $45.8 \%$. The study [29] with the longest ERS (32 weeks) had an adherence of $75.4 \%$.

\section{Adherence in routine practice}

Two studies took place in routine practice $[28,33]$. Adherence levels were 36.7\% [28] and 37.6\% [33]. Mean adherence across both studies was $37.2 \%$. Both studies were leisure centre-based.

\section{Adherence in trials}

Three studies were RCTs [29, 31, 32]. Adherence levels ranged from 41.1 to $75.4 \%$ and the mean adherence across all studies was $55.3 \%$. Two RCTs [29, 32] used ERSs involving regular face-to-face consultations and telephone calls. Adherence levels were 75.4 [29] and 59.6\% [32]. Mean adherence across both studies was $71.7 \%$. The other RCT [31] was leisure centre-based and had an adherence of $41.1 \%$.

\section{Long-term physical activity levels}

Two RCTs [29, 30] assessed the effects of ERSs on longterm physical activity levels among patients referred for mental health reasons (Table 6). Chalder et al. [29] asked participants to record physical activity levels in the week before assessment. These were converted into MET minutes [36] of physical activity per week (MET $=$ metabolic equivalent of the task as a ratio to the basal rate). Murphy et al. [30] assessed exercise levels using the 7-day Physical Activity Recall Scale (7D-PAR) [37].

When combining results from 4, 8 and 12 months, Chalder et al. [29] recorded a significant between group difference in the number of patients doing $\geq 1000$ MET minutes of physical activity per week in favour of the intervention group. After adjusting for all covariates, Murphy et al. [30] recorded a non-significant between group difference in 7D-PAR scores at 12 months in favour of the intervention group.

\section{Secondary outcomes}

A secondary aim of this review was to assess differences in ERS uptake/adherence in mental health referrals compared to non-mental health referrals (Table 5).

\section{Uptake and adherence in mental health referrals vs. non-mental health referrals}

Six studies [27, 28, 30, 33-35] assessed this outcome (Table 5). One of these was a RCT [31] and five were in a routine practice setting [27, 28, 33-35]. All comparator groups received the same ERS intervention as their respective mental health referral group.

\section{Uptake in mental health referrals vs. non-mental health referrals}

Five studies [27, 28, 31, 34, 35] assessed uptake. Mental health referral uptake ranged from 42.3 to $83.2 \%$, and comparator group uptake ranged from 27.1 to $85.8 \%$. Four of these studies [27, 28, 31, 35] assessed leisure centre-based ERS. Uptake in leisure centre-based ERSs ranged from 54.5 to $83.2 \%$ for mental health referrals and 67.7-85.8\% in comparator groups. Mean uptake across these four studies was $56.4 \%$ for all mental health referral participants and $71.2 \%$ for comparator groups. The other study [34] involved yoga classes and had an uptake of $42.3 \%$ for mental health referrals and $27.1 \%$ for the comparator group.

Four studies [27, 28, 34, 35] took place in routine practice. Uptake ranged from 42.3 to $82.6 \%$ in mental health referrals and $27.1-78.9 \%$ in comparator groups. Mean uptake across these studies was $55.3 \%$ for mental health referrals and $70.2 \%$ for comparator groups. Three of the studies in routine practice $[27,28,35]$ were leisure centre-based. Uptake of mental health referrals in the leisure centre-based studies ranged from 54.4 to $82.6 \%$, with a mean uptake of $55.5 \%$ across all three studies. Uptake of non-mental health referrals in the leisure centre-based 
Table 3 Study intervention details

\begin{tabular}{|c|c|c|c|c|}
\hline Study & Length & Type of ERS & Frequency of sessions & Duration of sessions \\
\hline Harrison 2005 [27] & 12 weeks & $\begin{array}{l}\text { Leisure centre-based: } \\
\text { - Consultations with exercise officer } \\
\text { - Access to leisure facilities and supervised } \\
\text { exercise sessions }\end{array}$ & $\begin{array}{l}\text { - Access to leisure facilities and exercise } \\
\text { sessions throughout (encouraged to attend } \\
\geq 2 \text { sessions/week } \\
\text { - Two consultations (weeks } 0,12 \text { ) }\end{array}$ & $\mathrm{N} / \mathrm{l}$ \\
\hline Crone 2008 [28] & 8-12 weeks & $\begin{array}{l}\text { Leisure centre-based: } \\
\text { - Gym sessions (majority) } \\
\text { - Swimming } \\
\text { - Circuits } \\
\text { - Exercise-to-music classes }\end{array}$ & Twice a week & $\mathrm{N} / \mathrm{l}$ \\
\hline $\begin{array}{l}\text { Chalder } \\
2012[29]\end{array}$ & 32 weeks & $\begin{array}{l}\text { Regular face-to-face consultations and tel- } \\
\text { ephone calls with physical activity facilitator }\end{array}$ & $\begin{array}{l}\text { Participants organise timing of: } \\
\text { - Three face to face consultations } \\
\text { - Ten telephone contacts }\end{array}$ & $30-60 \mathrm{~min}$ \\
\hline Murphy 2012 [30] & 16 weeks & $\begin{array}{l}\text { Leisure centre-based: } \\
\text { - Face to face consultations \& telephone } \\
\text { contact with exercise professional } \\
\text { - Access to one to one exercise instruction } \\
\text { \& group classes }\end{array}$ & $\begin{array}{l}\text { - Access to exercise instruction and classes } \\
\text { throughout } \\
\text { - Two consultations (weeks 0, 16) } \\
\text { - One telephone contact (week 4) }\end{array}$ & $\mathrm{N} / \mathrm{l}$ \\
\hline $\begin{array}{l}\text { Moore } \\
2013[31]\end{array}$ & 16 weeks & $\begin{array}{l}\text { Leisure centre-based: } \\
\text { - Face to face consultations \& telephone } \\
\text { contact with exercise professional } \\
\text { - Access to one to one exercise instruction } \\
\text { \& group classes }\end{array}$ & $\begin{array}{l}\text { - Access to exercise instruction and classes } \\
\text { throughout } \\
\text { - Two consultations (weeks } 0,16) \\
\text { - One telephone contact (week 4) }\end{array}$ & $\mathrm{N} / \mathrm{l}$ \\
\hline $\begin{array}{l}\text { Forsyth } \\
2015[32]\end{array}$ & 12 weeks & $\begin{array}{l}\text { Regular face-to-face consultations and } \\
\text { telephone calls with dietician/exercise } \\
\text { physiologists }\end{array}$ & Once every two weeks & $30-60 \mathrm{~min}^{\mathrm{a}}$ \\
\hline $\begin{array}{l}\text { Tobi } \\
2017[33]\end{array}$ & 20-26 weeks & $\begin{array}{l}\text { Leisure centre-based: } \\
\text { - Motivational/educational classes } \\
\text { - Access to group exercise } \\
\text { - Healthy walks } \\
\text { - Gym sessions } \\
\text { - Swimming/water workouts }\end{array}$ & $\mathrm{N} / \mathrm{I}$ & $\mathrm{N} / \mathrm{l}$ \\
\hline $\begin{array}{l}\text { Avery } \\
2020[34]\end{array}$ & Lifelong referral & $\begin{array}{l}\text { Therapeutic yoga classes in person and via } \\
\text { video link with yoga instructor }\end{array}$ & Up to 8 classes a week & $60 \mathrm{~min}$ \\
\hline $\begin{array}{l}\text { Morgan } \\
2020[35]\end{array}$ & 16 weeks & $\begin{array}{l}\text { Leisure centre-based: } \\
\text { - Face to face consultations \& telephone } \\
\text { contact with exercise professional } \\
\text { - Access to one to one exercise instruction } \\
\text { \& group classes }\end{array}$ & $\begin{array}{l}\text { - Access to exercise instruction and classes } \\
\text { throughout } \\
\text { - Two consultations (weeks } 0,16) \\
\text { - One telephone contact (week 4) }\end{array}$ & $\mathrm{N} / \mathrm{l}$ \\
\hline
\end{tabular}

${ }^{\mathrm{a}}=$ information obtained from author, $N / /$ No information provided, ERS exercise referral scheme

studies ranged from 67.7 to $78.9 \%$, with a mean uptake of $70.7 \%$ across all three studies. The other study based in routine practice [34] involved yoga classes and had an uptake of $42.3 \%$ for all mental health referrals and $27.1 \%$ for non-mental health referrals.

One study was a RCT [31]. Mental health referral uptake was $83.2 \%$ and comparator group uptake was 85.8\%. This ERS was leisure centre-based.

Two studies [31, 35] performed between group statistical analyses. In a trial setting, Moore et al. [31] discovered a non-significant difference in favour of greater uptake in the comparator group. In a routine practice setting, Morgan et al. [35] discovered a significant difference in favour of greater uptake in the comparator group.

\section{Adherence in mental health referrals vs. non-mental health referrals}

Three studies [28, 31, 33] assessed adherence to leisure centre-based ERS. Adherence ranged from 36.7 to $41.1 \%$ in mental health referrals and from 47.0 to $55.5 \%$ in comparator groups. Mean adherence across these studies was $39.3 \%$ for mental health referrals and $49.9 \%$ for comparator groups.

Two studies $[28,33]$ took place in routine practice. Mental health referral adherence levels were $36.7 \%$ [28] and $37.6 \%$ [33], with a mean adherence of $37.3 \%$ across both studies. Comparator group adherence levels were $48.8 \%$ in Crone et al. [28] and 47\% in Tobi et al. [33], with a mean adherence of $48.4 \%$ across both studies.

One study [31] was a RCT. Mental health referral adherence was $41.1 \%$ and comparator group adherence was $55.5 \%$. 
Table 4 Clinical effectiveness of ERS on mental health symptoms

\begin{tabular}{|c|c|c|c|c|}
\hline Study details & Outcome measure & $\begin{array}{l}\text { Outcome } \\
\text { assessment } \\
\text { timings }\end{array}$ & Short-term results ERS vs. $C$ & Long-term results ERS vs. C \\
\hline $\begin{array}{l}\text { Chalder } \\
2012 \text { [29] } \\
\text { Trial }\end{array}$ & BDI-II & $4,8,12$ months & $\begin{array}{l}4 \text { months adjusted between group dif- } \\
\text { ference in mean BDI-II score } \\
=-0.54 \text { ( } 95 \% \mathrm{Cl}-3.06 \text { to } 1.99) \mathrm{P}=0.68\end{array}$ & $\begin{array}{l}\text { Combined } 4,8 \text { and } 12 \text { months adjusted } \\
\text { between group difference in mean } \\
\text { BDI-II score }=-1.20 \text { ( } 95 \% \text { Cl }-3.42 \text { to } 1.02) \\
P=0.29\end{array}$ \\
\hline $\begin{array}{l}\text { Murphy } 2012 \text { [30] } \\
\text { Trial }\end{array}$ & HADS & 12 months & Did not assess & $\begin{array}{l}\text { HADS depression } \\
12 \text { months adjusted between group } \\
\text { difference in HADS depression score }= \\
-1.39(95 \% \mathrm{Cl}-2.60 \text { to }-0.18) \mathrm{P}<0.05 \\
\text { HADS anxiety } \\
12 \text { months adjusted between group } \\
\text { difference in HADS anxiety score }=-1.56 \\
(95 \% \mathrm{Cl}-2.75 \text { to }-0.38) \mathrm{P}<0.05\end{array}$ \\
\hline $\begin{array}{l}\text { Forsyth } \\
2015 \text { [32] } \\
\text { Trial }\end{array}$ & DASS-21 & 3 months & $\begin{array}{l}\text { DASS-21 depression subscale } \\
\text { ERS difference from baseline }=-2.1 \\
C \text { difference from baseline }=-4.0 \\
\text { Between group difference } P=0.1 \\
\text { DASS- } 21 \text { anxiety subscale } \\
\text { ERS difference from baseline }=-1.4 \\
C \text { difference from baseline }=-3.0 \\
\text { Between group difference } P=0.08 \\
\text { DASS-21 stress subscale } \\
\text { ERS difference from baseline }=-1.5 \\
C \text { difference from baseline }=-1.8 \\
\text { Between group difference } P=0.06 \\
\text { Total DASS-21 scores } \\
\text { ERS difference from baseline }=-5.1 \\
C \text { difference from baseline }=-6.1 \\
\text { Between group difference } P=0.04\end{array}$ & Did not assess \\
\hline
\end{tabular}

ERS exercise referral scheme group, $C$ comparator group, $C$ c confidence interval, HADS Hospital Anxiety and Depression Scale, BDI-II Beck depression inventory (version II) score, DASS-21 Depression, Anxiety and Stress Scale, $P<0.05=$ significant difference

Two of the studies [31,33] performed between group statistical analyses. In a trial setting, Moore et al. [31] discovered a significant difference in favour of greater adherence in the comparator group. In a routine practice setting, Tobi et al. [33] also discovered a significant difference in favour of greater adherence in the comparator group.

\section{Discussion}

The aims of this review were to evaluate: (1) clinical effectiveness of ERSs for mental health symptoms; (2) uptake and adherence of participants referred for mental health reasons in ERSs; (3) effects of ERSs on long-term physical activity levels in mental health participants. Uptake and adherence levels were also compared between mental health referrals and non-mental health referrals as a secondary outcome. This was to address the current evidence gap on this topic [16].

The short-term symptom improvement in ERS groups involving regular face-to-face consultations and telephone calls was not significant. Long-term improvement in symptoms for those taking part in leisure centre-based
ERSs was statistically significant, however, it is important to emphasise this is based on the findings of a single study [30]. No leisure centre-based ERS studies assessed short-term clinical effectiveness. When combining studies in trial and routine practice settings, regular face-toface consultations and telephone calls had the highest mean uptake and adherence levels [29, 32]. Only two studies [29, 30], both RCTs, measured the impact of ERSs on long-term physical activity levels in participants referred for mental health reasons. Regular face-to-face consultations and telephone calls [29] seemed to be more effective at increasing physical activity levels after 12 months than the leisure centre-based ERS [30].

Uptake and adherence to ERSs in mental health referrals was also compared to figures for uptake and adherence among those referred for other conditions. Although this comparison was not the primary aim of this review, it provided context and a point of reference for the uptake/adherence outcomes. Studies assessing both groups in leisure centre-based ERSs all recorded higher uptake $[27,28,31,35]$ and adherence $[28,31,33]$ in non-mental health referrals. The yoga-based ERS [34] was the only study with higher uptake levels in mental 
Table 5 ERS uptake and adherence in mental health referrals

\begin{tabular}{|c|c|c|c|c|}
\hline Study details & ERS information & Outcome measure & $\begin{array}{l}\text { Results } \\
\text { 1. Uptake } \\
\text { 2. Adherence }\end{array}$ & $\begin{array}{l}\text { Results in non-MH referrals (if } \\
\text { applicable) } \\
\text { 1. Uptake } \\
\text { 2. Adherence }\end{array}$ \\
\hline $\begin{array}{l}\text { Harrison } \\
2005[27] \\
\text { Routine practice }\end{array}$ & 12 weeks leisure centre-based & Attended first appointment & $\begin{array}{l}\text { 1. Attended first appointment } \\
\text { - } \mathrm{MH}=280 \text { (uptake } 82.6 \% \text { ) } \\
\text { 2. N/I }\end{array}$ & $\begin{array}{l}\text { 1. Attended first appointment } \\
\text { - } C=4945 \text { (uptake } 78.9 \% \text { ) } \\
\text { 2. N/I }\end{array}$ \\
\hline $\begin{array}{l}\text { Crone } 2008 \text { [28] } \\
\text { Routine practice }\end{array}$ & $\begin{array}{l}\text { 8-12 weeks leisure centre- } \\
\text { based }\end{array}$ & $\begin{array}{l}\text { Uptake } \\
\text { - Attended first session } \\
\text { Completed } \\
\text { - Attended } \geq 80 \% \text { of scheduled } \\
\text { sessions }\end{array}$ & $\begin{array}{l}\text { 1. Uptake } \\
\text { - } \mathrm{MH}=79 \text { (uptake 59.0\%) } \\
\text { 2. Completed } \\
\text { - } \mathrm{MH}=29 \text { (adherence 36.7\%) }\end{array}$ & $\begin{array}{l}\text { 1. Uptake } \\
\text { - C= } 1917 \text { (uptake 69.3\%) } \\
\text { 2. Completed } \\
\text { - C= } 935 \text { (adherence 48.8\%) }\end{array}$ \\
\hline $\begin{array}{l}\text { Chalder } \\
2012 \text { [29] } \\
\text { Trial }\end{array}$ & $\begin{array}{l}32 \text { weeks regular face-to-face } \\
\text { consultations and telephone } \\
\text { calls }\end{array}$ & $\begin{array}{l}\text { Failed to attend } \\
\text { - Did not attend first ERS } \\
\text { session } \\
\text { Received adequate dose } \\
\text { - Had } \geq 5 \text { sessions }\end{array}$ & $\begin{array}{l}\text { 1. Failed to attend } \\
\text { - ERS group }=11 \text { (uptake } \\
94.5 \%) \\
\text { 2. Received adequate dose at } \\
4 \text { months } \\
\text { - ERS group }=102(59.6 \% \\
\text { adherence) } \\
\text { Received adequate dose at } 8 \\
\text { months } \\
\text { - ERS group }=129(75.4 \% \\
\text { adherence) }\end{array}$ & Did not assess \\
\hline $\begin{array}{l}\text { Moore } \\
2013[31] \\
\text { Trial }\end{array}$ & 16 weeks leisure centre-based & $\begin{array}{l}\text { Did not enter } \\
\text { Partial attendance } \\
\text { (0-16 weeks) } \\
\text { Completed }\end{array}$ & $\begin{array}{l}\text { 1. Did not enter } \\
\text { - } \mathrm{MH}=52 \text { (uptake } 83.2 \%) \\
\text { 2. Partial attendance } \\
\text { - } \mathrm{MH}=152 \\
\text { Completed } \\
\text { - } \mathrm{MH}=106 \text { (adherence } 41.1 \% \text { ) }\end{array}$ & $\begin{array}{l}\text { 1. Did not enter } \\
-\mathrm{C}=109 \text { (uptake } 85.8 \%) \\
\text { Adjusted OR } 0.82(95 \% \mathrm{Cl} 0.57 \\
\text { to } 1.17 \text { ) } \\
\text { 2. Partial attendance } \\
-\mathrm{C}=294 \\
\text { Completed } \\
-\mathrm{C}=367 \text { (adherence } 55.5 \%) \\
\text { Adjusted OR } 0.57(95 \% \mathrm{Cl} 0.43 \\
\text { to } 0.75 \text { ) }\end{array}$ \\
\hline $\begin{array}{l}\text { Forsyth } \\
2015 \text { [32] } \\
\text { Trial }\end{array}$ & $\begin{array}{l}12 \text { weeks regular face-to-face } \\
\text { consultations and telephone } \\
\text { calls }\end{array}$ & $\begin{array}{l}\text { Declined referral } \\
\text { Discontinued participation }\end{array}$ & $\begin{array}{l}\text { 1. Declined referral } \\
\text { - ERS group }=9 \text { (uptake } 85.2 \% \text { ) } \\
\text { 2. Discontinued participation } \\
\text { - ERS group }=21 \text { (adherence } \\
59.6 \% \text { ) }\end{array}$ & Did not assess \\
\hline $\begin{array}{l}\text { Tobi } \\
2017 \text { [33] } \\
\text { Routine practice }\end{array}$ & $\begin{array}{l}20-26 \text { weeks leisure centre- } \\
\text { based }\end{array}$ & $\begin{array}{l}\text { Adherence } \\
\text { - Attended } \geq 80 \% \text { of scheduled } \\
\text { sessions } \\
\text { - Two recorded progress } \\
\text { assessments }\end{array}$ & $\begin{array}{l}\text { 1. } \mathrm{N} / \mathrm{I} \\
\text { 2. Adherence } \\
\text { - } \mathrm{MH}=53 \text { (adherence 37.6\%) }\end{array}$ & $\begin{array}{l}\text { 1. } N / I \\
\text { 2. Adherence } \\
-C=263 \text { (adherence } 47.0 \% \text { ) } \\
\text { - Between group difference } P \\
=0.04\end{array}$ \\
\hline $\begin{array}{l}\text { Avery } \\
2020[34] \\
\text { Routine practice }\end{array}$ & $\begin{array}{l}\text { Unlimited number of in person } \\
\text { or video link yoga classes }\end{array}$ & $\begin{array}{l}\text { Follow through/uptake } \\
\text { - Attendance at } \geq 1 \text { yoga class }\end{array}$ & $\begin{array}{l}\text { 1. Uptake } \\
\text { - } \mathrm{MH}=63 \text { (uptake 42.3\%) } \\
\text { Stress/anxiety (42\%) } \\
\text { Depression (40\%) } \\
\text { Post-traumatic stress disorder } \\
\text { (45\%) } \\
\text { 2. N/I }\end{array}$ & $\begin{array}{l}\text { 1. Uptake } \\
-C=74 \text { (uptake } 27.1 \%) \\
\text { 2. N/I }\end{array}$ \\
\hline $\begin{array}{l}\text { Morgan } \\
2020[35] \\
\text { Routine practice }\end{array}$ & 16 weeks leisure centre-based & $\begin{array}{l}\text { Did not take up } \\
\text { Uptake }\end{array}$ & $\begin{array}{l}\text { 1. Uptake } \\
\text { - MH only = } 4677 \text { ( } 54.4 \% \\
\text { uptake) } \\
\text { - } \mathrm{MH}+\mathrm{CHD}=3730 \text { ( } 61.9 \% \\
\text { uptake) } \\
\text { - All MH }=8407 \text { ( } 57.5 \% \text { uptake) } \\
\text { 2. N/I }\end{array}$ & $\begin{array}{l}\text { 1. Uptake } \\
\text { - } C=10,699 \text { ( } 67.7 \% \text { uptake) } \\
\text { - OR } 0.79,95 \% \text { Cl } 0.74 \text { to } 0.84 \\
\text { 2. N/I }\end{array}$ \\
\hline
\end{tabular}

* = information obtained from author, $\mathrm{MH}$ mental health, $\mathrm{C}$ comparator, ERS exercise referral scheme, $\mathrm{N} / \mathrm{I}$ no information available, $\mathrm{CHD}$ coronary heart disease, $S D$ standard deviation, $O R$ odds ratio, $C l$ confidence interval, $P<0.05=$ significant difference 
Table 6 Effects of ERS on long-term physical activity in mental health referrals

\begin{tabular}{|c|c|c|c|}
\hline Study details & Outcome measure & Outcome assessment & Results ERS vs. C \\
\hline $\begin{array}{l}\text { Chalder } \\
2012 \text { [29] } \\
\text { Trial }\end{array}$ & $\begin{array}{l}\text { MET minutes of physical activity a week } \\
\text { - Meeting current exercise guidelines if MET } \\
\geq 1000\end{array}$ & $4,8,12$ months & $\begin{array}{l}\text { Participants doing } \\
\geq 1000 \text { MET minutes } \\
\text { of physical activity per } \\
\text { week (\%): } \\
4 \text { months } \\
\text { - ERS }=52 \% \\
-C=43 \% \\
8 \text { months } \\
\text { - ERS }=63 \% \\
-C=49 \% \\
12 \text { months } \\
\text { - ERS = 58\% } \\
-C=40 \% \\
\text { Between group differ- } \\
\text { ence at } 4 \text { months } \\
\text { Adjusted OR 1.58 } \\
\text { (95\%Cl } 0.94 \text { to 2.66) P } \\
=0.08 \\
\text { Between group differ- } \\
\text { ence using combined } \\
4-, 8-\text { and } 12 \text {-month } \\
\text { data } \\
\text { Adjusted OR 2.27 } \\
\text { (95\%Cl } 1.32 \text { to 3.89) P } \\
=0.003\end{array}$ \\
\hline $\begin{array}{l}\text { Murphy } \\
2012[30] \\
\text { Trial }\end{array}$ & 7-D PAR & 12 months & $\begin{array}{l}12 \text { months adjusted } \\
\text { between group differ- } \\
\text { ence in 7D-PAR score } \\
=\text { OR } 1.06 \text { ( } 95 \% \text { Cl } 0.73 \\
\text { to } 1.55 \text { ) } P>0.05\end{array}$ \\
\hline
\end{tabular}

ERS exercise referral scheme group, $C$ comparator group, $S D$ standard deviation, $M H$ mental health, $C H D$ coronary heart disease, $N / /$ no information available, $C$ confidence interval, 7-D PAR 7-day physical activity recall, MET metabolic equivalent of the task, $O R$ odds ratio, $P<0.05=$ significant difference

health referrals. Nonetheless, uptake levels for mental health participants in this study were still lower than in any mental health referral group in leisure centre-based ERS.

There are several potential reasons as to why ERSs involving regular face-to-face consultations and telephone calls were found to be ineffective in improving symptoms compared to usual care in a control group [29, 32]. It is possible that the ERSs did not increase physical activity levels sufficiently to affect the symptoms [29]. Participants involved were also aware of their underlying condition and had voluntarily sought treatment. Additionally, trial participants are likely to already have greater motivation to change their lifestyle if they have agreed to take part in the study in the first place, whether they are allocated to the intervention or the control arm. Therefore, even though control groups received usual care, they may still have taken part in exercise or concurrently received other forms of effective treatment.

Both studies [29, 32] which involved regular face-toface consultations and telephone calls were trials. It is difficult to say unequivocally whether the improved uptake and adherence levels in these studies were due to the type of ERS undertaken or the study setting. Nevertheless, both studies $[29,32]$ did achieve greater uptake and adherence levels than the one leisure centre-based trial [31].

Avery et al. [34] was the only study with a higher level of uptake in mental health referrals compared to nonmental health referrals, but it was nevertheless lower than in any of the mental health referral groups in leisure centre-based ERSs [27, 28, 31, 35]. However, since only army veterans were allowed to sign up, the patient population is not directly comparable to the other studies. Therefore, although mental health referral uptake levels were lower than in other studies, the fact that mental health participants were more likely to attend the yoga classes than participants referred for physical health reasons merits further exploration. One possible explanation is that the more mindful and meditative nature of yoga makes it more appealing than standard gym sessions for people with mental health conditions.

Of those studies that collected data on uptake and adherence within both mental health referrals and nonmental health referrals [27, 28, 31,33-35], only two [28, 33] provided information on the mean ages for both groups. In both studies, mental health referrals had a lower level of uptake [28] and adherence [28, 33], but 
both also recorded a lower mean age in this group than their physical health counterparts. Other studies not included in this review have found that increasing age is positively correlated with greater ERS uptake levels [3840]. This suggests that age could be acting as a confounding factor in mental health referrals and may be partly responsible for the lower levels of uptake and adherence in this group. It is also important to stress that most ERSs were designed to help those with chronic physical health conditions, which usually have an older age of onset compared with mental health conditions [28, 41, 42]. Tobi et al. [33] showed that people who were referred to ERSs for reasons of mental ill health were likely to be younger than those referred for physical health reasons. The researchers found that older participants referred to the schemes because of their mental health diagnoses were less likely to drop out than younger participants, and older males were the more likely to complete the programmes [33]. The relationship between the success of ERSs for those with mental health referrals and patient age merits further research.

\section{Results in the context of previous research and implications for policy and practice}

This is the first review to look at ERSs and mental health in participants referred specifically for mental health reasons. Previous reviews have indicated that ERSs are beneficial to both mental health $[20,21]$ and psychological wellbeing [17], but these have been part of wider reviews that have included other conditions [17, 20,21]. Some of the included studies assessed mental health symptoms in those participants referred for non-mental health reasons $[43,44]$. Although not based in a primary care setting, one study found that ERSs ameliorated symptoms of male prisoners referred for mental health treatment [45].

The low uptake and adherence levels in mental health referrals suggests that the approach to ERSs within this population needs to change, with the standard leisure centre ERSs seemingly not having the same acceptability as it does for non-mental health referrals. Within the trial-based studies assessing uptake and adherence [29, 31, 32], ERSs involving regular face-to-face consultations and telephone calls $[29,32]$ had greater levels of uptake and adherence compared to leisure centre-based ERSs [31]. This could signify one-to-one meetings with health professionals (with no instant exercise obligations), are generally more appealing and less daunting to individuals presenting with mental health conditions. Both studies $[29,32]$ also adopted motivational interview techniques during meetings, suggesting that it may be beneficial to incorporate this into future ERS. Previous research supports this conclusion. Busch et al. [46] discovered that the majority of depressed individuals would be interested in exercise programmes, but see their depressive symptoms as a barrier, whilst Rouse et al. [47] found that autonomy support significantly improved intrinsic motivation. Screening patients for motivation levels before referral could also be beneficial in assessing suitability. ERSs should also be engaging and individualised to patients, as it has been shown that higher levels of attendance are associated with participant satisfaction with such interventions rather than the degree of severity of depression [48].

Flexibility in the delivery of the ERSs could improve participants' level of satisfaction and engagement. This is particularly important in the context of mental health, in which the cyclical nature of conditions, such as depression, is likely to result in setbacks [49]. Research has investigated factors that affect the decisions of those with serious mental illness to initiate physical activity. It highlighted the particular importance of participants' autonomy to decide their levels of participation in the activity [19]. Participants also considered it beneficial to know beforehand what they should expect the activity to entail and that it could be adapted to their needs [19]. Such knowledge, contributed to a supportive atmosphere, which was required to make exercise a success in this population. This all points towards the requirements that ERSs be tailored, individualised and personalised for people referred for mental health reasons [28], and that activities should be designed specifically for this group. An individualised and more holistic approach would enable consideration of aspects such as social circumstances, motivation, the availability of support, and cost $[19,49]$. Schemes should prioritise promoting enjoyment and the promotion of autonomy through joint decision making in the early stages of the physical activity $[19,49]$. These findings strengthen the argument made in this review that more mindful exercises such as yoga, which was used by Avery et al. [34], may be particularly beneficial for this patient group. Previous research indicating that yoga is beneficial for depression [50] and anxiety symptoms [51] further supports this assertion and strengthens the case for mindful exercise classes to be considered as part of ERS.

It has been shown that social support is required to help an individual with mental ill health to start physical activity in the community $[19,49,52]$, and that this support should be provided by someone who is trusted and/ or well-known to the individual $[19,53]$, such as health professionals [54], family members or friends [55]. The interpersonal relationship between the participant and their support team has been shown to play a big role in giving individuals with serious mental illness the confidence to start a new physical activity [19]. Previous research has also shown that individuals with depression 
who have several supportive social relationships show improved symptoms in response to the exercise treatment [56]. A non-judgemental, supportive atmosphere among peers and staff is particularly important for individuals with mental health conditions [19]. Formation of groups that are specifically tailored to the improvement of mental health could help to create the feeling of a shared identity among participants and responsibility towards others, which is known to be important for the engagement of people who attend group based physical activities [49, 52, 53, 57, 58].

The long-term physical activity results reported in Chalder et al. [29] suggest that having extra face-to-face consultations and telephone calls is more effective at encouraging individuals to maintain long-term physical activity levels, compared to leisure centre-based ERS programmes [30] with less frequent contact. Additional meetings may contribute to the support network of the participants. It is important to note, however, that this finding is only based on three studies and there were no routine practice studies assessing regular face-toface consultations and telephone calls. Some of the leisure centre-based ERS studies already incorporate two face-to-face consultations [27, 30, 31, 35], but increasing this number further may improve adherence for mental health referrals.

Another important aspect, outside the scope of this review, is cost-effectiveness. Previous research suggests that ERSs are cost-effective for fully adherent participants [21]. Individual RCTs have also indicated that leisure centre-based ERSs for mental health referrals [59] and walking programmes for depression [60] can be costeffective. This shows ERSs are a viable approach for managing patients who present with mental health conditions in primary care, but it is important to find the ERS programmes with the best symptom control and uptake to achieve optimum value for money. Participants may be less inclined to take up and maintain physical activity if there is a financial cost $[19,49]$. Low socio-economic status of participants has been found to have a negative effect on their uptake, adherence to and completion of the schemes, irrespective of the primary reason for referral [35, 61]. Regardless of whether monetary support is provided to help an individual to initiate the activity, that activity must be affordable in the long term for people to sustain their participation. Therefore, building an exercise support network for referred participants outside of paid classes could play a vital role in maintaining increased physical activity levels. The inclusion of motivational techniques may also help with initiation and maintenance of the schemes.

\section{Strengths and limitations of evidence and review}

A key strength of this review is the inclusion of both RCTs and studies undertaken in routine practice. The high internal validity of RCTs made the clinical effectiveness findings more reliable. However, RCTs may not be the most appropriate way to measure what uptake and adherence would be like in the real world. Data from routine practice have greater external validity, making this a better representation of the mental health population in primary care. It is therefore essential that a circumspect approach is taken when interpreting combined uptake and adherence results from RCTs and studies from routine practice.

The large amount of heterogeneity between studies made it difficult to evaluate ERS. There were different types, lengths and settings for ERS, and different outcome measures. Ideally, ERSs would be assessed according to these variables. Lack of research into clinical effectiveness and long-term physical activity levels in particular means this cannot be achieved.

The wide range of outcome measures made any direct comparison of these studies difficult. For clinical effectiveness, all three studies [29, 30, 32] used different measuring scales. Additionally, it is difficult to accurately measure physical activity levels. Both Murphy et al. [30] and Chalder et al. [29] used methods that only recorded physical activity in the week leading up to assessment, meaning participants may have increased exercise levels solely during this period. Not disclosing assessment timings would be one way to address this. The simple uptake definition of whether a participant attended a session after referral, made results for this outcome more reliable when collating and comparing data. However, different adherence definitions made this outcome less comparable. Chalder et al. [29] defined adherence as receiving $\geq 5$ ERS sessions, which was under $50 \%$ of the 13 available. This is significantly less than the $\geq 80 \%$ attendance required in other studies to be classified as an adherer $[28,33]$, potentially explaining the higher levels of adherence recorded by Chalder et al. [29].

There were limitations in a number of the studies included. Blinding was an issue in RCTs [29-32] due to the nature of ERSs making this impossible. There was also a high risk of attrition bias, with numerous participants dropping out. Furthermore, participants in some studies did not provide reasons for withdrawal [29, 30, 32].

\section{Areas for future research}

There is a sizeable gap in the literature regarding trials assessing the effect of ERSs on mental health symptoms in those referred for mental health reasons. No published research was found to have investigated the 
short-term effectiveness of leisure centre-based ERSs on symptoms in participants referred for mental health reasons. This is important, considering that most ERSs are currently leisure centre based. More studies assessing ERSs involving individualised programmes and mindful exercises are also needed, as are RCTs comparing different types of ERSs for mental health referrals. Research is also required on the effects of ERSs on long-term physical activity in mental health referrals; longer follow ups in future trials could help achieve this.

\section{Conclusions}

There is evidence, albeit limited, that leisure centre-based ERSs can improve long-term mental health symptoms in those referred for mental health reasons. Evidence also suggests that ERSs involving regular face-to-face consultations and telephone calls are more effective than leisure centre-based ERSs in terms of increasing uptake, adherence, and long-term physical activity levels; however, this type of programme has not been assessed in routine practice. Future research is required to explore what types of ERS are most clinically effective, including the consideration of mindful exercise options such as yoga. Services should also consider including more mindful exercise options to improve the quality of their provision.

Existing ERSs could be improved through application of more individual tailoring, motivational techniques, and the provision of more face-to-face consultations, and social support.

\section{Abbreviations}

BDI-II: Beck Depression Inventory version II; Cl: Confidence interval; DASS-21: Depression, Anxiety and Stress Scale - 21 items; ERS: Exercise referral scheme; HADS: Hospital Anxiety and Depression Scale; MET: Metabolic equivalent of task; NICE: National Institute for Health and Care Excellence; OR: Odds ratio; RCT: Randomised controlled trial; 7D-PAR: 7-Day Physical Activity Recall Scale.
\end{abstract}

\section{Supplementary Information}

The online version contains supplementary material available at https://doi. org/10.1186/s12889-022-12638-7.

\section{Additional file 1. Original protocol.}

Additional file 2. Literature search strategy used in the databases of Medline, PsycInfo, CINAHL, Scopus, and the Cochrane Library.

Additional file 3. Reasons for exclusion of full-text articles during study selection stage.

Additional file 4: Quality assessment of included studies. Figure S1. Risk of bias graph for RCTs. Figure S2. Risk of bias summary for RCTs.

\section{Acknowledgements}

We thank the University of Sheffield library resources for allowing access to scientific databases.

\section{Authors' contributions}

STP undertook the initial literature review, supervised by EG who contributed to the original review protocol and advised on the search strategy, study selection, data extraction and quality assessment. STP and KM wrote the first draft of the manuscript. STP and GM were responsible for the final study selection and quality assessment and STP and EK were responsible for the data extraction. JF and NP, with the other authors, reviewed and revised the manuscript critically for important intellectual content. All authors read and approved the final version of the manuscript.

\section{Funding}

This project was conducted at the University of Sheffield School of Health and Related Research as part of STP's Master of Public Health qualification. There was no additional funding available for conducting this review. JF is supported by a University of Manchester Presidential Fellowship (P123958) and a UK Research and Innovation Future Leaders Fellowship (MR/T021780/1) and has received consultancy fees from Parachute $\mathrm{BH}$ for a separate project.

\section{Availability of data and materials}

All the data generated in this study is provided in the published article (Fig. 1; Tables 1, 2, 3, 4, 5 and 6) or the additional supporting files (Figure S1, Figure S2, Table S1, Table S2).

\section{Declarations}

Ethics approval and consent to participate

Ethical approval was not required for this systematic review.

Consent for publication

Not applicable.

\section{Competing interests}

The authors declare that they have no competing interests.

\section{Author details}

${ }^{1}$ School of Medicine, University of Liverpool, Liverpool, UK. ${ }^{2}$ College of Health, Wellbeing and Life Sciences, Sheffield Hallam University, Sheffield, UK. ${ }^{3}$ Division of Psychology and Mental Health, University of Manchester, Manchester, UK. ${ }^{4}$ Department of Allied Health Professionals, Sheffield Hallam University, Sheffield, UK. ${ }^{5}$ School of Health and Related Research (ScHARR), University of Sheffield, Sheffield, UK.

Received: 24 January 2021 Accepted: 24 January 2022

Published online: 07 February 2022

\section{References}

1. National Collaborating Centre for Mental Health, National Institute for Health and Care Excellence. Common mental health disorders: identification and pathways to care: NICE; 2011.

2. National Institute of Health and Care Excellence. Depression 2020 [Available from: https://cks.nice.org.uk/depression\#!topicSummary. Accessed 31 March 2020.

3. National Institute of Health and Care Excellence. Generalized anxiety disorder 2017 [Available from: https://cks.nice.org.uk/generalized-anxie ty-disorder\#!topicSummary. Accessed 31 March 2020.

4. Lamers F, van Oppen P, Comijs HC, Smit JH, Spinhoven P, van Balkom AJ, et al. Comorbidity patterns of anxiety and depressive disorders in a large cohort study: the Netherlands Study of Depression and Anxiety (NESDA). J Clin Psychiatry. 2011;72(3):0-.

5. Mental Health Foundation. Stress: Are we coping? London: Mental Health Foundation; 2018.

6. Penedo FJ, Dahn JR. Exercise and well-being: a review of mental and physical health benefits associated with physical activity. Curr Opin Psychiatry. 2005;18(2):189-93.

7. Caspersen CJ, Powell KE, Christenson GM. Physical activity, exercise, and physical fitness: definitions and distinctions for health-related research. Public health rep. 1985;100(2):126-31. 
8. Sharon-David $\mathrm{H}$, Tenenbaum $\mathrm{G}$. The effectiveness of exercise interventions on coping with stress: research synthesis. Studies in Sport Humanities. 2017;22(22):19-29.

9. Fox KR. The influence of physical activity on mental well-being. Public Health Nutr. 1999;2(3a):411-8.

10. De Mello MT, de Aquino Lemos V, Antunes HKM, Bittencourt L, Santos-Silva R, Tufik S. Relationship between physical activity and depression and anxiety symptoms: a population study. J Affect Disord. 2013;149(1-3):241-6.

11. Firth J, Siddiqi N, Koyanagi A, Siskind D, Rosenbaum S, Galletly C, et al. The Lancet Psychiatry Commission: a blueprint for protecting physical health in people with mental illness. The Lancet Psychiatry. 2019;6(8):675-712.

12. Ruegsegger GN, Booth FW. Health benefits of exercise. Cold Spring Harbor perspectives in medicine. 2018:8(7):a029694.

13. Schuch F, Vancampfort D, Firth J, Rosenbaum S, Ward P, Reichert T, et al. Physical activity and sedentary behavior in people with major depressive disorder: a systematic review and meta-analysis. J Affect Disord. 2017;210:139-50.

14. Scholes S, Neave A. Health Survey for England 2016: Physical activity in adults. 2017.

15. Population Health Team. NHS Digital. Health Survey for England 2018 Adult's health-related behaviours. National Statistics. 2019.

16. National Institute for Health and Care Excellence. Physical activity: exercise referral schemes: National Institute for Health and Care Excellence, 2014 [Available from: https://www.nice.org.uk/guidance/ph54. Accessed 14 April 2020.

17. Pavey T, Taylor A, Fox K, Hillsdon M, Anokye N, Campbell J, et al. Effect of exercise referral schemes in primary care on physical activity and improving health outcomes: systematic review and meta-analysis. Bmj. 2011;343:d6462

18. bristol.gov.uk. Physical activity referral programmes for people with health conditions 2021 [Available from: https://www.bristol.gov.uk/socialcare-health/physical-activity-referral-programmes. Accessed 14 October 2021.

19. Quirk H, Hock E, Harrop D, Crank H, Peckham E, Traviss-Turner G, et al. Understanding the experience of initiating community-based group physical activity by people with serious mental illness: A systematic review using a meta-ethnographic approach. European Psychiatry. 2020:1-18.

20. Rowley N, Mann S, Steele J, Horton E, Jimenez A. The effects of exercise referral schemes in the United Kingdom in those with cardiovascular, mental health, and musculoskeletal disorders: a preliminary systematic review. BMC Public Health. 2018;18(1):949.

21. Pavey T, Anokye N, Taylor A, Trueman P, Moxham T, Fox K, et al. The clinical effectiveness and cost-effectiveness of exercise referral schemes: a systematic review and economic evaluation. Health Technol Assess. 2011;15(44):i.

22. Moher D, Liberati A, Tetzlaff J, Altman DG, Group P. Preferred reporting items for systematic reviews and meta-analyses: the PRISMA statement. PLoS med. 2009;6(7):e1000097.

23. Thomas J, Kneale D, McKenzie JE, Brennan SE, Bhaumik S. Determining the scope of the review and the questions it will address. Cochrane Handbook for Systematic Reviews of Interventions. 2019:13-31.

24. Higgins JP, Altman DG, Gøtzsche PC, Jüni P, Moher D, Oxman AD, et al. The Cochrane Collaboration's tool for assessing risk of bias in randomised trials. Bmj. 2011;343:d5928.

25. Cochrane Collaboration. Review Manager (RevMan)[Computer Program] Version 5.2. 3. Copenhagen: The Nordic Cochrane Centre; 2012. HEALTH PSYCHOLOGY REVIEW. 2014;17.

26. Institute of Health Economics. IHE Quality Appraisal Checklist for Case Series Studies. 2016.

27. Harrison RA, McNair F, Dugdill L. Access to exercise referral schemes -- a population based analysis. J Public Health (Oxf). 2005;27(4):326-30.

28. Crone D, Johnston LH, Gidlow C, Henley C, James DV. Uptake and participation in physical activity referral schemes in the UK: an investigation of patients referred with mental health problems. Issues Ment Health Nurs. 2008;29(10):1088-97.

29. Chalder M, Wiles NJ, Campbell J, Hollinghurst SP, Haase AM, Taylor AH, et al. Facilitated physical activity as a treatment for depressed adults: randomised controlled trial. Bmj. 2012;344.
30. Murphy SM, Edwards RT, Williams N, Raisanen L, Moore G, Linck P, et al. An evaluation of the effectiveness and cost effectiveness of the National Exercise Referral Scheme in Wales, UK: a randomised controlled trial of a public health policy initiative. J Epidemiol Community Health. 2012;66(8):745-53.

31. Moore GF, Raisanen L, Moore L, Din NU, Murphy S. Mixed-method process evaluation of the welsh national exercise referral scheme. Health Education. 2013.

32. Forsyth A, Deane FP, Williams P. A lifestyle intervention for primary care patients with depression and anxiety: a randomised controlled trial. Psychiatry Res. 2015;230(2):537-44.

33. Tobi P, Kemp P, Schmidt E. Cohort differences in exercise adherence among primary care patients referred for mental health versus physical health conditions. Primary Health Care Research Development. 2017; 18(5):463-71.

34. Avery TJ, Schulz-Heik RJ, Friedman M, Mahoney L, Ahmed N, Bayley PJ. Clinical yoga program utilization in a large health care system. Psychol Serv. 2020.

35. Morgan K, Rahman M, Moore G. Patterning in Patient Referral to and Uptake of a National Exercise Referral Scheme (NERS) in Wales From 2008 to 2017: A Data Linkage Study. International Journal of Environmental Research Public Health. 2020;17(11):3942.

36. Jette M, Sidney K, Blümchen G. Metabolic equivalents (METS) in exercise testing, exercise prescription, and evaluation of functional capacity. Clinical cardiology. 1990;13(8):555-65.

37. Hayden-Wade HA, Coleman KJ, Sallis JF, Armstrong C. Validation of the telephone and in-person interview versions of the 7-day PAR. Med Sci Sports Exerc. 2003;35(5):801.

38. Dugdill L, Graham RC, McNair F. Exercise referral: the public health panacea for physical activity promotion? A critical perspective of exercise referral schemes; their development and evaluation. Ergonomics. 2005;48(11-14):1390-410.

39. Sowden SL, Breeze E, Barber J, Raine R. Do general practices provide equitable access to physical activity interventions? Br J Gen Pract. 2008;58(555):e1-8.

40. Gidlow C, Johnston LH, Crone D, Morris C, Smith A, Foster C, et al. Socio-demographic patterning of referral, uptake and attendance in Physical Activity Referral Schemes. Journal of public health. 2007;29(2):107-13.

41. Gidlow C, Johnston LH, Crone D, James D. Attendance of exercise referral schemes in the UK: a systematic review. Health Education Journal. 2005;64(2):168-86.

42. Johnston LH, Warwick J, De Ste Croix M, Crone D, Sldford A. The nature of all'inappropriate referrals' made to a countywide physical activity referral scheme: Implications for practice. Health Education Journal. 2005;64(1):58-69.

43. Isaacs A, Critchley J, Tai SS, Buckingham K, Westley D, Harridge S, et al. Exercise Evaluation Randomised Trial (EXERT): a randomised trial comparing GP referral for leisure centre-based exercise, communitybased walking and advice only. HEALTH TECHNOLOGY ASSESSMENTSOUTHAMPTON-. 2007;11(10).

44. Duda JL, Williams GC, Ntoumanis N, Daley A, Eves FF, Mutrie N, et al. Effects of a standard provision versus an autonomy supportive exercise referral programme on physical activity, quality of life and well-being indicators: a cluster randomised controlled trial. International Journal of Behavioral Nutrition Physical Activity. 2014;11(1):10.

45. O'Toole S, Maguire J, Murphy P. The efficacy of exercise referral as an intervention for Irish male prisoners presenting with mental health symptoms. International Journal of Prisoner Health. 2018.

46. Busch AM, Ciccolo JT, Puspitasari AJ, Nosrat S, Whitworth JW, StultsKolehmainen MA. Preferences for exercise as a treatment for depression. Ment Health Phys Act. 2016;10:68-72.

47. Rouse PC, Ntoumanis N, Duda JL, Jolly K, Williams GC. In the beginning: role of autonomy support on the motivation, mental health and intentions of participants entering an exercise referral scheme. Psychol Health. 2011;26(6):729-49.

48. Krogh J, Lorentzen AK, Subhi Y, Nordentoft M. Predictors of adherence to exercise interventions in patients with clinical depression-a pooled analysis from two clinical trials. Mental Health Physical Activity. 2014;7(1):50-4. 
49. Machaczek KK, Allmark P, Pollard N, Goyder E, Shea M, Horspool M, et al. Integrating physical activity into the treatment of depression in adults: A qualitative enquiry. Health \& Social Care in the Community; 2021.

50. Cramer H, Lauche R, Langhorst J, Dobos G. Yoga for depression: A systematic review and meta-analysis. Depress Anxiety. 2013;30(11):1068-83.

51. Javnbakht M, Kenari RH, Ghasemi M. Effects of yoga on depression and anxiety of women. Complement Ther Clin Pract. 2009;15(2):102-4.

52. Crone D, Smith A, Gough B.'I feel totally at one, totally alive and totally happy': a psycho-social explanation of the physical activity and mental health relationship. Health Educ Res. 2005;20(5):600-11.

53. Soundy A, Freeman P, Stubbs B, Probst M, Roskell C, Vancampfort D. The psychosocial consequences of sports participation for individuals with severe mental illness: A metasynthesis review. Advances in Psychiatry. 2015;2015.

54. Mason OJ, Holt R. Mental health and physical activity interventions: a review of the qualitative literature. Journal of Mental Health. 2012;21(3):274-84.

55. Lassenius O, Arman M, Söderlund A, Wiklund-Gustin L. Motivation Does not Come with an Ending — It's the Beginning of Something New: Experiences of Motivating Persons with Psychiatric Disabilities to Physical Activity. Issues Ment Health Nurs. 2014;35(9):713-20.

56. Hallgren M, Lundin A, Tee FY, Burström B, Forsell Y. Somebody to lean on: Social relationships predict post-treatment depression severity in adults. Psychiatry research. 2017;249:261-7.

57. Soundy A, Kingstone T, Coffee P. Understanding the psychosocial processes of physical activity for individuals with severe mental illness: A meta-ethnography. Ment Illn. 2012;2:1-20.

58. Crone D. Walking back to health: a qualitative investigation into service users' experiences of a walking project. Issues Ment Health Nurs. 2007;28(2):167-83.

59. Edwards RT, Linck P, Hounsome N, Raisanen L, Williams N, Moore L, et al. Cost-effectiveness of a national exercise referral programme for primary care patients in Wales: results of a randomised controlled trial. BMC Public Health. 2013;13(1):1021.

60. Gusi N, Reyes MC, Gonzalez-Guerrero JL, Herrera E, Garcia JM. Cost-utility of a walking programme for moderately depressed, obese, or overweight elderly women in primary care: a randomised controlled trial. BMC Public Health. 2008;8(1):231.

61. Oliver EJ, Dodd-Reynolds C, Kasim A, Vallis D. Inequalities and Inclusion in Exercise Referral Schemes: A Mixed-Method Multi-Scheme Analysis. Int J Environ Res Public Health. 2021;18(6):3033.

\section{Publisher's Note}

Springer Nature remains neutral with regard to jurisdictional claims in pub-

lished maps and institutional affiliations.

Ready to submit your research? Choose BMC and benefit from:

- fast, convenient online submission

- thorough peer review by experienced researchers in your field

- rapid publication on acceptance

- support for research data, including large and complex data types

- gold Open Access which fosters wider collaboration and increased citations

- maximum visibility for your research: over 100M website views per year

At BMC, research is always in progress.

Learn more biomedcentral.com/submissions 